\title{
0 avanço da rede hoteleira em Salvador e na Costa dos Coqueiros - 1996 a 2006
}

\author{
Iata Oliver Fernandes Silva ${ }^{1}$
}

\begin{abstract}
Resumo
Este trabalho faz uma avaliação do recente avanço da rede hoteleira na cidade de Salvador e na Costa dos Coqueiros. Analisam-se os fatores que convergem para uma nova fase de desenvolvimento nacional, desde o plano Collor, que abriu um período de mudanças na economia e na organização produtiva no Brasil. Verifica-se a estabilização da economia - o Plano Real, que articulou um novo modelo de desenvolvimento. Essas medidas construíram as condições nacionais necessárias ao novo plano de expansão da hotelaria nacional. 0 desenvolvimento da rede hoteleira atende a uma lógica de zoneamento turístico ocorrida no estado da Bahia e, especialmente, na cidade de Salvador. O estudo levanta, ainda, as novas fontes de financiamento para os empreendimentos e faz uma análise da situação da rede já instalada comparando com as mudanças por que ela passa e, por último, examina os efeitos positivos e negativos dessa nova fase da hotelaria da Bahia. Quanto à metodologia, trata-se de uma pesquisa de campo, com abordagem qualitativa, que se utiliza de fontes bibliográficas e entrevistas para a composição dos dados.
\end{abstract}

Palavras-chave: hotel, rede, avanço, Bahia, economia

\begin{abstract}
This work is an assessment of the progress of recent hotel network in the city of Salvador and Costa dos Coqueiros. They were examined in this study the factors that converge to a new stage of national development, since the Collor Plan, which opens a period of changes in the economy and productive organization in Brazil. The work follows checking the stabilization of the economy, the Real Plan, which articulates a new model of development. These measures build the conditions necessary for the new national plan for expansion of hotels nationally. The development of the hotel network serves the logic of zoning news occurred in the state of Bahia and in the city of Salvador. The work raises the new sources of financing for enterprises and makes an analysis of the situation of the network already installed compared with the changes it passes, and finally examines the positive and negative effects of this new phase of hotels in Bahia. As the methodology it is a search field, with qualitative approach, which it used for library resources and interviews for the composition of the data.
\end{abstract}

Keyword: hotel; network; advance; Bahia; economy

\footnotetext{
${ }^{1}$ Mestrando em Hospitalidade, Universidade Anhembi Morumbi — UAM, São Paulo-SP, Brasil. E-mail: iata_oliver@yahoo.com.br. Endereço: Rua Manoel Joaquim Alves, Cond. Sol Nascente, 113 A - Apto 302 Salvador, Bahia. CEP 41.770-165
} 


\section{Introdução}

No início dos anos de 1990, o governo Collor abre um período de mudanças na economia e na organização produtiva no Brasil, determinadas pela abertura comercial, reestruturação da indústria e redefinição do papel do Estado.

Diversas análises têm sido feitas para verificar os efeitos dessas alterações no cenário econômico nacional. Em contribuição para tais análises, esta pesquisa faz uma releitura da pesquisa de Martins (2003) com a abordagem feita, agora, da cidade de Salvador e do litoral norte do estado da Bahia sobre a oferta hoteleira, no que se refere ao planejamento macroeconômico.

Esta pesquisa tem, pois, como objetivo geral, compreender como se deu o avanço da rede hoteleira em Salvador e no litoral norte da Bahia, no período de 2000 a 2006. O desenvolvimento do tema gerou a necessidade de contextualizar o cenário econômico nacional a partir do governo Collor (1990-1992) e, principalmente, em 1994, com o Plano Real, quando o País sofreu profundas mudanças.

A amplitude do tema impôs a necessidade de limitar o objeto de estudo que é a rede hoteleira. Apenas hotéis instalados ou reformados, no período de 2000 a 2006, e com mais de cem unidades habitacionais (UHS) foram verificados. Nesse sentido, fizeram parte então do universo da pesquisa os hotéis abaixo referidos: 
Hotéis estudados em salvador e na costa dos coqueiros com mais de 100 uhs entre os anos de 2000 e 2006

\begin{tabular}{|c|c|c|c|}
\hline OPERAÇÃO & REDE & HOTEL & ORIGEM \\
\hline Reformado & Hotéis Othon & Bahia Othon & Brasil \\
\hline Reformado & Accor & Sofitel Salvador & França \\
\hline Instalado & Accor & Sofitel Sauípe & França \\
\hline Instalado & Accor & Sofitel Suítes & França \\
\hline Instalado & Super Clubs & Super Clubs Breezes & Jamaica \\
\hline Instalado & Marriott & Marriott Costa do Sauípe & EUA \\
\hline Instalado & Marriott & Renaissance Costa do Sauípe & EUA \\
\hline Vendido & Pestana & Pestana Salvador* & Portugal \\
\hline Instalado & Vila Galé & Vila Galé Salvador & Portugal \\
\hline Vendido & Blue Tree & Blue Tree Morro do Conselho & Nacional \\
\hline Instalado & Independente & Pizza Plaza Hotel & Nacional \\
\hline Instalado & Accor & Íbis & França \\
\hline Instalado & Accor & Mercure & França \\
\hline Instalado & InterContinental & Holiday Inn & EUA \\
\hline Instalado & Pestana & Convento do Carmo & Portugal \\
\hline Vendido & Accor & Club Méd. Itaparica* & França \\
\hline Instalado & Vila Galé & Vila Galé Marés Resort & Portugal \\
\hline Instalado & Independente & Web Hotel & Nacional \\
\hline Instalado & Iberostar & Iberostar Praia do Forte & Espanha \\
\hline Vendido & Espírito Santo & Praia do Forte Eco Resort* & Espanha \\
\hline Inst./Vendido & Pestana & Pousadas de Sauípe & Portugal \\
\hline
\end{tabular}

Fonte: $\mathrm{O}$ autor.

* Permaneceu com o mesmo nome de fantasia

O trabalho baseou-se em pesquisas bibliográficas e entrevistas semi-estruturadas com profissionais que já atuam no mercado desde o ano de 1996. Trata-se, portanto, de um estudo de campo com abordagem qualitativa.

Para o entendimento do avanço hoteleiro aqui estudado, primeiro é preciso compreender o cenário econômico-político nacional dos anos de 1990, que serviu de pano de fundo para as redes hoteleiras multinacionais se instalarem no Brasil.

\section{A modernização do mercado nacional}

A partir da Constituição federal de 1988 (C.F./88), o País iniciou seu processo de liberalização comercial. Nesse ano, foram adotadas as primeiras medidas nesse sentido, com a redução de alíquotas de importação e a adoção de medidas restringindo determinadas barreiras tarifárias. Mas foi a partir do governo Collor que a nova tendência 
tomou força, com a eliminação da maior parte das restrições não-tarifárias e o estabelecimento de um cronograma de redução das alíquotas de importação.

O novo governo, empossado em 1990, aprofundou as mudanças no regime de importações do País, iniciadas em 1988, com destaque para a eliminação das restrições não-tarifárias, a manutenção da redução gradual das alíquotas de importação, agora através de um cronograma de redução tarifária, e a abolição da maior parte dos regimes especiais de importação (AZEVEDO e PORTUGAL, p. $3)$.

O Plano Collor provocou uma abertura da economia que forçou a reestruturação produtiva nacional. Essa abertura, no entanto, não obedeceu a critérios que pudessem ser considerados como parte de uma política consistente e conseqüente.

Conforme indica a publicação $\mathrm{n}^{\circ} 11$ da revista Nova Técnica, uma política de modernização da produção há que contemplar aspectos como:

- incentivos fiscais;

- investimentos em pesquisa e desenvolvimento (P\&D);

- créditos subsidiados;

- intervenção direta do Estado no processo produtivo;

- parcerias público-privadas;

- criação de zonas francas e de processamento para exportação (ZPE).

Os empresários nacionais então se viram numa situação de crise, em que precisavam enfrentar a concorrência internacional e não tinham muita condição de modernizar-se. A saída adotada para a modernização do mercado nacional foi a atração de multinacionais para aqui se instalarem. Para tal, algumas medidas governamentais foram tomadas, como a abertura de indústrias de eletrônicos. Sobre esse setor, afirma André Nassif:

Dentre os setores da economia brasileira, o complexo eletrônico foi um dos que mais sofreram os impactos adversos da liberalização comercial, implementada com maior vigor a partir de 1990. Estudos empíricos estimam um incremento do coeficiente de penetração das importações (importações/consumo aparente) de 9,6\% em 1990 para 66,1\% em 2001, figurando a eletrônica como o setor mais afetado pela concorrência com produtos importados no período (2003, p. 180).

Muitas empresas multinacionais viam então, no Brasil, um ambiente perfeito: um campo industrial defasado, com enorme necessidade de desenvolvimento e recebendo incentivos do governo. Nassif continua analisando:

Não por acaso, diversas empresas nacionais foram forçadas a retirar-se do mercado logo na primeira metade da década de 90, ou, quando não foi essa a opção, tiveram de deslocar-se para nichos de mercado bastante específicos (2003, p. 201).

Barros e Goldenstein, ainda no decorrer do processo de modernização do mercado nacional, afirmaram sobre a tradicional empresa nacional que, "[...] as decisões de investimento recomeçaram como única garantia de sobrevivência num mundo que passou a ser competitivo. Aquelas que não mudaram sua atuação ou fizeram muito tarde já morreram ou morrerão" (1997, p.14). 
O novo cenário produtivo nacional criou um modelo de desenvolvimento com suas bases no setor privado. Nesse aspecto, a efetivação do desenvolvimento estaria condicionada à manutenção da democracia, estabilização da economia e à continuidade das reformas do Estado.

Em 1994, o então ministro da Fazenda Fernando Henrique Cardoso (FHC) lançou o Plano Real que aprofundou as mudanças já ocorridas e que é entendido como a síntese de um novo modelo de desenvolvimento, cuja essência consiste na liberação total do mercado. Esse Plano contou com a estabilização inflacionária que tornou possível uma previsibilidade orçamentária para as classes média e baixa, aumentando o poder de compra, provocando um aumento no consumo, afetando também a carteira dos bancos e incentivando a ampliação do crédito por causa do fim do float inflacionário. Esses dois últimos fatores trouxeram como conseqüência a ampliação do mercado interno, bem como dos fundos de pensão.

Também o orçamento empresarial se viu numa situação de previsibilidade, recriando condições de segurança aos investidores, que estavam tendo um horizonte de médio e longo prazo fundamental para as decisões de investimento.

O Plano Real, uma ferramenta poderosa para a modernização da estrutura produtiva nacional, possibilitou acesso a bens de capital mais modernos, que aumentaram os ganhos de produtividade, permitindo, assim, num segundo momento, melhores condições de competitividade. A aquisição desses bens gerou um déficit comercial que foi financiado pela entrada de capital das empresas multinacionais que passaram a investir aqui.

Wander Ulhôa relata:

Dessa forma, é forçoso reconhecer que a política econômica do Plano Real está explicitamente articulada com os interesses do capital estrangeiro em detrimento do capital nacional. Nesse sentido, as políticas públicas estiveram quase sempre em consonância com as estratégias adotadas pelas empresas estrangeiras. É o caso, por exemplo, da concessão de créditos através do BNDES que concede empréstimos a taxas de juros subsidiadas às empresas estrangeiras, seja para a aquisição de empresas nacionais, seja para a importação de equipamentos e máquinas importadas. Além disso, a captação de recursos no exterior a taxas expressivamente menores favoreceu as grandes empresas estrangeiras instaladas no Brasil (2007).

Quando o presidente da república FHC (1995-2002) tornou a reforma do Estado e a privatização importantes pontos de seu governo, sob forte influência da corrente neoliberal, que ganhou força mundial a partir do final dos anos de 1970, na América Latina, e características próprias com o Consenso de Washington, seu conteúdo básico previa a adoção do Estado mínimo; controle inflacionário; ajuste fiscal; privatizações; abertura comercial e o fim das restrições ao capital e às instituições financeiras estrangeiras.

Vale lembrar que o Consenso de Washington pregava principalmente que a nova fase do desenvolvimento capitalista modificaria o papel do Estado Nacional, que passaria a ser apenas regulador, afastando o Estado da esfera produtiva. "Os estados, especialmente na periferia, foram conscientemente enfraquecidos [...] a fim de favorecer o predomínio sem contrapesos dos interesses das grandes empresas" (BARON, 1994). 
Entre as políticas neoliberais, a política de privatização praticada no Brasil talvez seja a mais característica, entre todas em escala internacional desde os últimos anos da década de 1970. Adotou-se aqui a concorrência, o fortalecimento do capital privado e a capitalização do Estado por meio das privatizações para controlar a balança comercial. Seguindo a cartilha neoliberal, o governo do estado da Bahia vendeu o Hotel da Bahia para o Tropical Hotels \& Resorts Brasil.

Para legitimar a desestatização, a C.F./88 afastou o Estado da esfera produtiva direta nos seguintes termos:

Art. 173. Ressalvados os casos previstos nesta Constituição, a exploração direta de atividade econômica pelo Estado só será permitida quando necessária aos imperativos da segurança nacional ou à relevante interesse coletivo, conforme definido em lei (BRASIL, 1988).

Assim, o Estado abandonou o papel de ator direto da atividade econômica, característica da fase nacional desenvolvimentista, e assumiu feição outra: o de agente regulador, conforme se lê em trecho da C.F./88.

Art. 174. Como agente normativo e regulador da atividade econômica, o Estado exercerá, na forma da lei, as funções de fiscalização, incentivo e planejamento, sendo este determinante para o setor público e indicativo para o setor privado (BRASIL, 1988).

Preparado o amparo legal, o governo $\mathrm{FHC}$ deu força ao processo de privatização brasileira e criou o Conselho Nacional de Desestatização (CND). Sancionou também a Lei das 20 Concessões, alargando o alcance do Plano Nacional de Desestatização (PND). Permitiu, ainda, a transferência ao setor privado de concessões para exploração de serviços públicos munido de dispositivos legais (BASTOS, 2003)

Antes, algumas limitações inibiam o investidor estrangeiro, o que deixou de existir com a Resolução n. ${ }^{\circ}$ 2.062/94 do Conselho Monetário Nacional (CMN). Como resultado de uma política madrasta, que acolhia os filhos alheios como sendo seus, se, no ano de 1995, a participação do capital estrangeiro nas privatizações ficou em torno de 4\% (US\$ 417,1 milhões), em 1996, ela foi de 14\%, US\$1.864,7 milhões (CMN, 1997).

Com todas as condições criadas, conforme exposto acima, em 1996, já se tinha uma ampla economia de mercado. Como o setor hoteleiro, por característica, dá suporte ao desenvolvimento dessas atividades aqui citadas, pois elas dependem de um turismo de negócio bem estruturado que possa acompanhar seu desenvolvimento, fez-se necessária a sua ampliação e modernização também.

Não foi só o turismo de negócio que ganhou espaço nesse projeto de desenvolvimento nacional, o de lazer também conquistou força a cada ano e contribuiu para o avanço da rede hoteleira internacional no Brasil.

A chegada das redes hoteleiras no Brasil, datada da década de 1970, período marcado por incentivos públicos e financiamentos concedidos pelo Estado em condições especiais, visava estimular a implantação deste e de outros setores ainda apáticos ou inexistentes aqui no Brasil. O marco da hotelaria internacional deu-se em 1971, com a inauguração do Hilton São Paulo. 
O Hilton São Paulo foi inaugurado em 1971, sendo um dos mais importantes hotéis da cidade de São Paulo, localizado no centro da megalópole na avenida Ipiranga. O hotel do centro encontra-se desativado desde fins de 2004, tendo-se transferido no mesmo ano para a região da Berrini-Marginal Pinheiros. Sua nova sede se localiza no Centro Empresarial Nações Unidas (WIKIPÉDIA, 2007).

O momento econômico favorável por que passava a economia brasileira nessa época e os incentivos públicos oferecidos favoreceram a abertura de outros hotéis de rede internacional: as redes Holiday Inn, Sheraton (Intercontinental), Meridian, Mediterranée, Novotel e Caesar Park. Esse avanço interrompeu-se na década seguinte, a "década perdida", diferente do que ocorreu nas economias européias e norte-americanas.

Foi só nos anos 1990 que a retomada do crescimento das redes hoteleiras internacionais, aqui no Brasil, voltou a ocorrer. As empresas multinacionais deslocaram-se num ritmo cada vez maior na economia mundial, adotando diversos modelos de gestão (franquia, arrendamento, fusão, aquisição, etc.), objetivando assim aproveitar as diversas oportunidades de negócio oferecidas pelo novo modelo de economia neo-liberal.

A estabilização econômica brasileira marcou o início de um novo ciclo de crescimento para a hotelaria no Brasil. A abertura comercial, a desregulamentação do mercado, as reformas do papel do Estado e um governo democrático, tudo isso foi fundamental para a criação de um ambiente favorável à entrada de investimentos estrangeiros. Assim, Lima afirma:

Embalados pela estabilização econômica e pela abertura comercial, os investidores das redes ganharam novo impulso da "década das reformas". Em 2002 os hotéis de rede respondem por cerca de $15 \%$ do total dos empreendimentos no País - operando 90.000 dos 600.000 quartos disponíveis - e esta participação deverá aumentar até o final da década (2003, p. 15).

Agora, se há algum fator diferente do visto nos anos 1970 que valha ser analisado, é a origem dos recursos para investimento, pois, no primeiro ciclo, eram recursos públicos e, agora, são os fundos de pensão que representam importantes agentes financiadores e passam a investir no setor hoteleiro, já que possuem enormes capitais e não vêem mais incentivos na especulação financeira. O modelo de financiamento adotado por esses fundos já é conhecido das redes hoteleiras, pois foi largamente aplicado na Europa. Vale lembrar que esses fundos detêm cerca de $70 \%$ dos hotéis de médio e grande porte nos EUA e na Europa.

Assim, em 1996, foi inaugurado o primeiro hotel construído com recursos dos fundos de pensão: o Sol Meliá São Paulo; e, em 2000, o primeiro na Bahia: o complexo hoteleiro Sauípe, com recursos da Previ (Previdência Privada dos Funcionários do Banco do Brasil).

Outro fator financiador foi a participação do mercado imobiliário nesse plano de expansão, canalizando os recursos especulativos da classe média e captando-os por meio de cotas e títulos dos empreendimentos.

O setor público, a partir de 1991, incentivou todo o setor turístico com recursos destinados à infra-estrutura pública. Trata-se do Programa de Desenvolvimento Turístico (PRODETUR) que empregou US\$ 670 (milhões). 
O governo aumentou também o investimento em marketing. Os recursos do Instituto Brasileiro de Turismo (EMBRATUR) que eram de R \$ 3 milhões, em 1994, passaram para R \$ 44 milhões em 2000 (EMBRATUR, 2006).

Também alguns fatores internacionais impulsionaram o crescimento do parque hoteleiro no Brasil. Ocorreu, pelo mundo, uma modernização dos serviços de hospedagem nos últimos anos, mas o Brasil não o acompanhou. Isso gerou a necessidade de atualizar-se, uma vez que, internamente, surgiram aspirações de desenvolvimento do mercado turístico como um setor independente: o turismo de lazer e de eventos.

Nesse novo contexto de desenvolvimento turístico, "o litoral nordeste apresenta-se como uma tradução localizada de um projeto nacional de turismo, que visa mudar a posição marginal do País entre os destinos turísticos mundiais" (CRUZ, 2000, p. 133).

Desde que assumiu o comando do Estado, em 1991, o novo governo identificou a necessidade de recuperar os índices de desenvolvimento da atividade turística [...] Tomando como referência as diretrizes do PRODETUR-BA [...], o governo estadual, gradualmente, deu início à implantação das estratégias direcionadas ao desenvolvimento do turismo no Estado (QUEIRÓS, 2002, p. 154).

Para alcançar tal posição, era preciso não só modernizar, mas ampliar o parque, para essa competição internacional. Os padrões mundiais de qualidade precisavam ser adotados; contudo as empresas nacionais não dispunham de know-how, reforçando a necessidade da chegada de multinacionais.

Os investimentos das redes internacionais têm demonstrado clara seletividade espacial, concentrando mais de $60 \%$ de suas unidades de hospedagem (hotéis e flats) na egião sudeste [...] seguida do nordeste [...] A lógica obedecida pelos investimentos obedece à própria dinâmica da globalização: privilegia os maiores centros de negócios, de lazer, capitais mais dinâmicas, centros demográficos e regiões particularmente vocacionadas pelo turismo (LIMA, 2003, p. 15-16).

A política do governo da Bahia, a partir de 1991, teve como objetivos básicos promover a desconcentração do desenvolvimento do turismo, bem como ampliar e melhorar a qualidade do produto turístico baiano.

Esta estratégia para o desenvolvimento do turismo, na Bahia, resultou, para o período de 1991 a 2000, em um crescimento da ordem de $221 \%$ no fluxo turístico receptivo. [...]

Em 1999, a cidade de Salvador já havia se classificado, no Brasil, como o $4 .^{\circ}$ portão de entrada para turistas estrangeiros.

$[\ldots]$

O setor hoteleiro tem sido um dos principais beneficiados pelo impulso turístico baiano. Em 1996, a taxa de ocupação média dos hotéis, em Salvador, era de 48\%, e a diária média em um estabelecimento de luxo não superava US\$ 50,00. Em 2000, a taxa de ocupação passou a 65,51\%, e a diária média, em estabelecimentos congêneres, para US\$120,00. De acordo com a Bahiatursa, os hotéis da categoria luxo foram os mais demandados, respondendo por cerca de $50 \%$ da taxa de 
ocupação, enquanto os hotéis das categorias superior e econômica participaram, respectivamente, com $23 \%$ e $18 \%$ (BNDES, 2001).

Objetivando colocar a Bahia no topo dos destinos turísticos brasileiros até 2005, o governo traçou um plano que criou uma geografia turística para o estado. A estratégia adotada visava promover a desconcentração do desenvolvimento turístico da Bahia, por meio da divisão do estado em sete áreas turísticas, tendo, em cada uma delas, no mínimo, um destino turístico principal. São elas: Costa dos Coqueiros, Baía de Todos os Santos, Costa do Dendê, Costa do Cacau, Costa do Descobrimento, Costa das Baleias e Chapada Diamantina.

Esse zoneamento teve efeito na expansão da rede hoteleira pelo estado. Neste trabalho, privilegia-se a Costa dos Coqueiros e a cidade de Salvador.

A Zona Turística da Costa dos Coqueiros compreende todo o litoral norte do estado da Bahia, no Brasil, estendendo-se por 193 quilômetros. No estado, entre a zona turística da Baía de Todos os Santos e o estado do Sergipe, [...] a Costa dos Coqueiros é cortada pela BA-099 em seus dois trechos: a Estrada do Coco e seu prolongamento, a Linha Verde (WIKIPEDIA, 2007).

Na cidade de Salvador, a expansão da rede hoteleira atende a uma lógica de zoneamento turístico como ocorre no estado, contudo não declarada, mas não menos evidente. $\mathrm{O}$ mercado imobiliário é que conduz as regras para que se implantem novos hotéis que se encontram na faixa da orla, combinados com a proximidade de centros comerciais ou turísticos.

\section{Efeitos do avanço da hotelaria na rede instalada}

A alta capacidade das redes hoteleiras de expandir-se horizontalmente além das próprias fronteiras para obter economia de escala, empregando técnicas de produção superior às das empresas locais e obtendo maiores benefícios, geraram um expressivo avanço da rede hoteleira em Salvador e na Costa dos Coqueiros a partir de 1996.

Esse avanço acarretou mudanças em todo o trade hoteleiro, pois transformou a hotelaria já instalada. Bull (1994) relaciona alguns fatores, comprovando que a sua introdução no mercado nacional possibilitou alterações no perfil da hotelaria no Brasil:

- Técnicas logísticas e experiência acumulada.

- Acesso à tecnologia sofisticada.

- Fontes mais amplas e baratas de pessoal.

- Planificação e competência para a preparação de pessoal.

- Sistemas informatizados e de contabilidade.

É importante mencionar, entre os principais efeitos da globalização, as alterações por que as empresas locais passaram para competir com as recém-chegadas multinacionais, demandando flexibilidade, agilidade e baixo custo e que podem ser consideradas como o que há de melhor para o mercado nacional, embora possa ser difícil e muitas vezes fatal para as empresas. 
Então, para a sobrevivência das empresas já instaladas, foi preciso adaptarem-se a práticas como flexibilidade na produção, no gerenciamento e marketing; redefinição de processos de trabalho e práticas de emprego, buscando sempre a diminuição dos custos. Um ponto crítico era o alto custo da folha de pagamento. Então surgiu a busca de um novo perfil de funcionário, que precisava ser flexível, ocorrendo também a sua substituição pela automação e eliminação de tarefas e setores.

A incorporação dessas novas tecnologias na hotelaria fez com que aumentasse a exigência do nível de qualificação dos funcionários, para que atendesse a um padrão internacional, inclusive no que se referia a conhecimentos de línguas estrangeiras. Com isso, aumentou também o nível de qualidade dos serviços prestados; contudo não houve um efetivo aumento na remuneração por categoria.

A força do capital externo chegou para uma competição altamente profissional, e as regras, que eram definidas pelo próprio mercado, sofreram uma forte influência internacional. Contudo nem sempre foi possível acompanhar essas mudanças, cabendo às empresas a criação de estratégias diferenciadoras para trabalharem em parcelas do mercado não interessantes para as multinacionais.

A segunda maior operadora nacional de hotéis, a tradicional rede Othon, apresentou sucessivos resultados negativos no final da década de 80 vendo-se obrigada a implementar, a partir dos anos 90, sucessivas transformações tecnológicas e organizacionais, imprescindiveis para manter-se atuante em um mercado tornado mais dinâmico e competitivo com o avanço das redes internacionais (LIMA, p. 37).

Vale complementar que a unidade Bahia Othon foi uma das poucas a apresentar resultado de caixa positivo nesse período, lucrando, na década de 1990, especialmente nos anos de 1992, 1993 e 1997 (MELLO apud LIMA, 2002).

A hotelaria, então em atividade no Brasil, foi instalada na década de 1970; vinte anos depois, havia uma necessidade de reinvestimento em infra-estrutura, no que diz respeito à reforma, modernização e ampliação. A reforma e a modernização tornaram-se necessárias por conta de os hotéis estarem obsoletos e, muitas vezes, sucateados em virtude de vinte anos de uso; e a ampliação, para gerar uma economia de escala. Então, uma vez resolvidos esses problemas, se conseguiria um custo de operação menor. Os dois principais hotéis de Salvador que serviram de exemplo são: o Sofitel Salvador, do grupo Accor, que foi totalmente reformado, aumentando de 203 para 206 Uhs - segundo seu ex-gerente, José Ozanir, a reforma melhorou significativamente a sua taxa de ocupação; e o antigo hotel Meridian, comprado pelo grupo Pestana em 2001, que também passou por uma reforma nesse ano, aumentando de 403 para 433 Uhs e de 11 para 20 salões de eventos. Esse fenômeno não é exclusivo da hotelaria, pois toda a indústria nacional passou por esse processo de implantação até a década de 1970; em seguida a "década perdida" tornou-se obsoleta e entrou em processo de sucateamento. A década de 1990 foi o momento, portanto, da recuperação.

Essa redução de custos mudou o perfil dos hotéis, cujo foco voltou-se para os serviços e não mais para as instalações. Assim, a matriz de classificação, reeditada em 1996, trouxe esse novo conceito. As grandes áreas de lazer foram adotadas apenas em empreendimentos que exploravam essas áreas como o centro de seu negócio, contudo isso só ocorreu em regiões de baixo custo de terreno e que tinham potencial natural a ser explorado. Isso 
justifica um dos motivos da expansão da hotelaria pela Costa dos Coqueiros. Em 2000, foi inaugurado, na Costa dos Coqueiros, o Complexo Costa do Sauípe. Esse fenômeno mudou as características dos novos empreendimentos como também dos já em funcionamento. As áreas de lazer passaram a ser aproveitadas como áreas de negócios, despontando aí um nicho de mercado: o turismo de eventos, que se tornou um importante aliado no combate à sazonalidade. Salvador recebeu, em 1994, um hotel com um centro de convenções: o Fiesta Hotel e o Fiesta Convention. Para não perder mercado, o Bahia Othon, seu concorrente direto, construiu um centro de convenções.

Outra tendência eram os ambientes projetados para gerar mais conforto e prazer, sem necessariamente recorrer à sofisticação e ao rebuscamento. O acolhimento tornou-se, assim, valorizado, buscando-se a hospitalidade por meio da arquitetura e da decoração.

Essas mudanças em projetos de construção e/ou reforma ficaram ainda mais profundas. Como a demanda tornou-se cada vez mais exigente em busca de consumir aquilo que parecesse pessoal, para um único hotel atender a todas as expectativas dos clientes, os altos custos tornariam o negócio inviável. Então as empresas diferenciaram o produto e reestruturaram-se os hotéis, numa grande estratégia de marketing, buscando conhecer os clientes para poder oferecer-lhes serviços desejáveis a cada um deles. Essa reestruturação envolveu também a arquitetura, pois dependia dela a prestação de certos serviços.

Vale lembrar que um produto diferenciado requer uma marca diferenciada. Sobre esse tema, Castlles comenta.

Quando a demanda de quantidade e qualidade tornou-se imprevisível; quando os mercados ficaram mundialmente diversificados $e$, portanto, dificeis de ser controlados; e quando o ritmo de transformação tecnológica tornou obsoletos os equipamentos de produção com objetivo único, o sistema de produção em massa ficou muito rígido e dispendioso para as características da nova economia. $O$ sistema produtivo flexível surgiu como uma possível resposta para superar essa rigidez (2001, p. 176).

Andrade (2000) também observa a respeito e descreve que os tipos de turismo existem em função das desigualdades de níveis pessoais e grupais, da diversidade dos modos de educação, do poder aquisitivo, da diversificação etária, das oportunidades e das necessidades atendidas. Cada produto turístico tem, pois, características especiais que devem ser levadas em conta quando se estabelecem as estratégias de segmentação que um hotel pretende adotar. O conhecimento dos diversos tipos de turismo torna possível o planejamento e a execução dos serviços de hospedagem, facilitando o atendimento às necessidades do hóspede.

Em Salvador, a rede Accor atua em vários segmentos, desde a hotelaria econômica até a de luxo. Ela inaugurou, no bairro do Rio Vermelho, dois hotéis de categoria econômica: o Ibis e o Mercure. Para esses hotéis, a rede apresenta uma proposta de hotel econômico (ACCOR HOTELS, 2006). E, para a categoria luxo, a Accor Hotels exibe a marca Sofitel, que é sinônimo de luxo, alta gastronomia e localização privilegiada nos mais importantes destinos de negócios e de lazer em todo o mundo (ACCOR HOTELS, 2006). A rede, que já tinha o Sofitel Salvador, inaugurou mais duas unidades no ano 2000, no Complexo Hoteleiro Sauípe: o Sofitel Costa do Sauípe e o Sofitel Suítes. 
Essa diversificação de marcas e tipos de hotéis enfraquece o sistema de classificação, pois há um grande número de espécies de hotéis, não mais os conhecidos cinco tipos em que se classificavam; contudo a internacionalização da hotelaria brasileira permite que se possam conhecer os tipos de serviços, mesmo estando no local de origem do turista. Na região observada, há apenas hotéis classificados no padrão cinco estrelas e não existe nenhum de categoria inferior.

A diversificação e a flexibilização dos negócios não ficam apenas na criação de diversas marcas para cada segmento de demanda ou no enfraquecimento de sistemas de classificação, atingem também os investimentos imobiliários. A atividade hoteleira requer um alto volume de investimento imobilizado, o que poderia ser um fator limitante para um avanço tão alto como se planejava. Então, as redes internacionais adotaram aqui uma estratégia já utilizada por elas na Europa e nos EUA. Elas se abriram para o mercado de capitais e fecharam parcerias com construtoras, incorporadoras e agentes institucionais regionais, bem como adotaram sistemas de financiamentos imobilizados. Trata-se do regime de time sharing, franquias e contratos de arrendamento. Dessa forma, o empreendimento Holiday inn adotou o time sharing, e o Complexo Costa do Sauípe arrendou os seus cinco hotéis.

Em outubro de 1998, a Companhia Transamérica passou a operar, em regime de arrendamento, o Hotel Transamérica Salvador Morro do Conselho, um empreendimento financiado por diversos fundos de pensão: Ecos, Faelba, Coelba, Previnor e Bases (LIMA, 2006, p.51).

Mesmo sendo uma tendência esses tipos de gestão, o grupo português Pestana, comprou um grande hotel em Salvador e passou a operá-lo: o Pestana Salvador. Inaugurou outro hotel em Salvador, por um regime especial de arrendamento, pois se trata de um prédio histórico e do patrimônio da Igreja Católica: o Hotel Convento do Carmo.

Essas estratégias de terceirização de investimentos permitem às empresas hoteleiras serem apenas operadoras, focando seus esforços na operação e possibilitando-lhes, assim, uma ampla expansão.

Bull (1994) concorda que a passagem do investimento de capital para a realização de acordo de gestão sem inversão se explica, em parte, pela natureza dos custos do investimento direto, comparados com os mercados disponíveis, e, em parte, pelo fato de que não há necessidade de que as empresas matrizes centralizem e internalizem o investimento. Os principais benefícios para a matriz fluem da operação e não da propriedade, desde que não existam conflitos de interesse.

Em resposta a essa grande força de negócios (marketing, vendas, operação), os hotéis locais e independentes passaram a organizar-se associativamente, numa estratégia que visa a fortalecer-se. $\mathrm{Na}$ área de atuação desta pesquisa, não há um hotel que passe pela linha de corte, que apresente a característica associativista, embora haja a presença da cadeia Provence com um hotel associado.

\section{Conclusões}

É facilmente percebível a mudança por que a hotelaria baiana passou graças à contribuição de know-how internacional e também da concorrência que os novos hotéis representam. 
Houve uma modernização do setor, com implantação de padrões internacionais de qualidade, barateamento das diárias, introdução de novas tecnologias e técnicas de gestão hoteleira e qualificação de mão-de-obra.

A chegada dos hotéis internacionais significou, também, a colocação do Brasil como um destino turístico na rota internacional, ou seja, a disponibilização dos hotéis nas principais centrais de reserva do mundo, ajudando a atrair novos turistas, aumentando o fluxo de entrada de divisas e, com isso, alcançando os principais objetivos, Com os investimentos na hotelaria nacional, mais turistas vêm ao País, aumentando, pois, o faturamento do setor e incentivando também novos investimentos.

Contudo o modelo de gestão mais utilizado por essas empresas deixa o País em situação de insegurança, causada pela volatilidade do capital externo. $\mathrm{O}$ modelo de arrendamento dos empreendimentos pelas operadoras internacionais, que coloca na linha de frente do financiamento o governo, os fundos de pensão e a classe média nacional, permite que, numa situação de retrocesso, as operadoras retirem suas bandeiras, ficando o capital nacional com o imobilizado do negócio e, por conseqüência, com o maior risco.

$\mathrm{O}$ avanço da rede hoteleira afetou, principalmente, dois segmentos da hotelaria. O primeiro refere-se aos hotéis de luxo: o Bahia Othon, o Sofitel Salvador (Quatro Rodas), o Meridian e o Eco Resort Praia do Forte, fortemente atingidos. Dessa forma, cada um deles tomou uma medida para não amargar prejuízos: o Bahia Othon optou por construir um centro de convenções, pois se trata de um hotel de rede com capacidade para continuar no mercado; o Sofitel Salvador entrou em profunda reforma e modernização, por ser também um hotel internacional com plena capacidade de recuperação, e assim o fez logo no princípio do período de modernização; o Meridian optou por retirar a bandeira do empreendimento; e o proprietário do Eco Resort Praia do Forte, um hotel independente, decidiu vender o empreendimento, uma vez que a concorrência dos resorts internacionais recéminaugurados na Costa dos Coqueiros desencorajou-o de tocar o negócio, porque se acostumara a trabalhar quase que sem concorrência desde a inauguração do investimento na década de 1970.

Outro segmento bastante atingido foi a hotelaria independente que não teve tanta capacidade de recuperação, pois os hotéis que aqui chegaram promoveram um serviço barato e de qualidade internacional, com uma economia de escala, tornando impossível à hotelaria instalada competir em igualdade. Nesse caso, a alternativa foi o endividamento para as reformas mais urgentes. Assim, esses empreendimentos sofreram para permanecer no mercado.

Não são poucas as críticas que controvertem os elogios do modelo de avanço da rede internacional ocorrida no Brasil nos últimos anos. No entanto o fato é que esse avanço, composto por modernização e ampliação da planta hoteleira, foi imprescindível para o novo plano de desenvolvimento nacional, traçado desde o início dos anos de 1990. Sozinha, a hotelaria nacional não teria capacidade de modernizar-se, enquadrando-se no padrão internacional, pois não detinha o know-how necessário para tal evolução. Mas há quem conteste que a volatilidade do capital internacional põe em risco a sustentabilidade do setor, requerendo do governo um comprometimento maior do que o pretendido com o modelo de estado mínimo. Ou seja, caso ocorra qualquer problema de fluxo de capital, o governo terá de subsidiar o investimento, em razão do risco de ver as multinacionais retirarem suas bandeiras do empreendimento e de o prejuízo para a economia e para o mercado ser ainda maior. 
Outro problema que essas redes internacionais representam para a economia nacional é que há um fluxo intenso do lucro do negócio para os países de origem que pouco é reinvestido na economia nacional, principalmente quando os clientes efetuam seus pagamentos via agências de viagem no país de origem e em cartão de crédito, porque, dessa forma, o dinheiro nem chega a circular no mercado nacional.

O Brasil encontra-se hoje numa situação muito mais austera que a encontrada no inicio da década passada, o que dá ao Estado uma independência para propiciar condições a um desenvolvimento nacional desde que não tenha de conceder tantas vantagens ao capital externo, pois assim o benefício maior também será externo.

Conclui-se, então, que, desde a década de 1990, o modelo de modernização implantado, não por uma completa opção, mas por uma falta de condição, coloca o Brasil numa inserção passiva no mercado internacional.

Como é um dos papéis de todo estudo acadêmico, o objetivo é contribuir para o amadurecimento das discussões sobre o tema ou temas que envolvam a economia, o turismo ou a atividade hoteleira da região analisada. Assim, este estudo não esgota o tema, apenas dá a sua contribuição, pois nenhuma pesquisa se esgota em si, ficando aqui o convite para quem se interessar dar a sua contribuição e continuidade ao estudo.

\section{Referências}

ACCOR HOTELS. Disponível em: www.accorhotels.com.br. Acessado em: 12 jun. 2006.

AZEVEDO, André Felipe Z. e PORTUGAL, Marcelo S. Abertura comercial brasileira e a instabilidade da demanda de importações. Universidade Federal do Rio Grande do Sul. Disponível em: < http://www.ufrgs.br/ppge/pcientifica/1997_05.pdf >. Acessado em: 20 maio 2007.

BARON, A. A. Estado, capitalismo e democracia na América LatIna. São Paulo, Paz e Terra, 1994.

BASTOS, Fábio Mendonça. Neoliberalismo e a recente política de privatização no Brasil: o caso da malha nordeste da rede ferroviária federal S.A. - RFFSA. Dissertação de Mestrado na Universidade Federal do Ceará. Fortaleza, 2003.

BRASIL. Constituição da República Federativa do Brasil . 40. ed. [local, editora?], 2007 (Col. Saraiva de Legislação).

BNDES - Área de Operações Industriais. As potencialidades turísticas do estado da Bahia. Brasília, 2001.

BULL, Adrian. La economía del sector turístico. Madrid, Alianza Editorial, 1994.

CASTELLS, Manuel. A sociedade em rede. São Paulo: Paz e Terra, 2001.

CMN. Relatório das privatizações. Brasília, 1997.

CRUZ, Rita de Cássia A. Política de turismo e território. São Paulo: Contexto, 2000.

IPEA - Instituto de Pesquisa Econômica Aplicada. Federalismo e dívida estadual no Brasil. Rio de Janeiro, 2002. 
LIMA, Renata Adriana Prosérpio Fontes. O avanço das redes hoteleiras internacionais no Brasil: 1994-2002. Tese de Doutorado em Ciências da Comunicação na Universidade de São Paulo. São Paulo, 2003.

MAANEN, John, Van. Reclaiming qualitative methods for organizational research: a preface. Administrative Science Quarterly, v. 24, n. ${ }^{04}$, dez. 1979, p. 520-6.

MARTINS, Nadia Proserpio. Novas vertentes da arquitetura hoteleira em São Paulo: o caso dos "apart"- hotéis. Dissertação de Mestrado na Faculdade de Arquitetura e Urbanismo da Universidade de São Paulo. São Paulo, nov. 2000.

NASSIF, André Luís Gomes. Liberalização comercial e eficiência econômica: a experiência brasileira. Tese de Doutorado em Economia da Indústria e da Tecnologia na Universidade Federal do Rio de Janeiro. Rio de Janeiro, 2003.

NOTA TÉCNICA. Política industrial no Brasil: o que é a nova política industrial, n. ${ }^{\circ} 11$, dez. 2005.

QUEIROZ, Lúcia Aquino de. Turismo na Bahia: estratégias para o desenvolvimento. Salvador, BA: EGBA, 2002.

ULHÔA, Wander. Estratégias competitivas no Brasil e abertura comercial na década de 90 . Revista Cesuc. Disponível em: < http://www.cesuc.br/revista/ed3/ESTRAT_COMP_NO_BRASIL_E_ABERTURA_COMERC_NA_DECADA_DE_90.pdf > Acesso em: 12 maio 2007.

WIKIPEDIA. Costa dos Coqueiros. Disponível em: < http://pt.wikipedia.org/wiki/Costa_dos_Coqueiros >. Acesso em: 12 jun. 2007. 